NEW SMALL VOLUME REBREATHING SYSTEM TO MEASURE CARDIOPULMONARY FUNCTION. FM Galioto, DS Brudno, RH Howard, O RIvera and UE Ruttimann, Children's Hospital Nat. Med Center, Dept. Cardiol. Wash, D.C. (Spon, by GC Rosenquist).

A new technique to measure effective pulmonary blood flow (QEP), lung tissue volume (analogous to lung water, VT) lung diffusing capacity (DL) and functional residual capacity (FRC) has been devised using a 2 cc dead space, non-flow or pressure restrlctive valve interfaced with a mass spectrometer, pneumotachograph and computer for rapld data analysis, including 02 consumption, minute ventilation and $\mathrm{CO}_{2}$ production during regular breathing. To test sensitivity, 32 New Zealand rabbits $(3-4 \mathrm{~kg})$ were anesthesized, intubated and ventilated. QEP, VT, DL and FRC were obtained by rebreathing $0.5 \%$ acetylene, $0.3 \%$ carbon monoxide and $10 \%$ helfum (balance $\mathrm{O}_{2}$ or room air) for up to 15 seconds avoiding recirculation and were consistent with coefficients of variation of $10 \%$ under varying hemodynamic conditions. In two rabbits with flow probes around pulmonary artery and aorta, QEP was $6.5 \%$ less than flow probe-derived total pulmonary or systemic flow. FRC varled less than $6 \%$ with known volumes as small as $20 \mathrm{cc}$. Infusion of $25 \mathrm{cc} / \mathrm{kg}$ saline to ralse cardlac output and VT increased mean QEP from 330 to $355 \mathrm{cc} / \mathrm{mln}(\mathrm{p}<01)$ and mean VT from 23.33 to $39.87 \mathrm{cc}(\mathrm{p}<.01)$, without changing DL or FRC. Add1tion of $5 \mathrm{~cm} \mathrm{H} 20$ PEEP increased mean FRC from 51.4 to $73.0 \mathrm{cc}$ (pr.01), w1 thout changing QEP ( 300 to $314 \mathrm{cc} / \mathrm{min}$ ), VT $(23.33$ to $20.79 \mathrm{cc})$ or DL $(0.880$ to $0.952 \mathrm{cc} / \mathrm{min} / \mathrm{mmHg})$. We anticipate that this non-invasive method will permit similar measurements at the bedside in critically 111 neonates.

THE TRIAD OF COMPLETE HEART BLOCK, ABSENCE OF THE

14 ATRIAL SEPTUM AND CONGENTTAL INTERRUPTION OF THE INFERIOR VENA CAVA. Otto Garcla, Ashok Mehta, Dolores Tamer, Grace Wolff, Arthur Pickoff, Pedro Ferrer, Stephen Malion, Leonard Sommer, Henry Gelband. Univ. of Miami School of Medicine, Depts. of Pediatrics and Medicine, Miami, Fla.

The assoctation of complete heart block (CHB) and interruption of the inferior vena cava (IIVC) has not been previously emphastzed. We analyzed the records of 29 patients (pts), age 1 day to 48 years, with anglographic documentation of IIVC with azygos continuation to a right or left superior vena cava. 28/29 pts had an associated intracardiac malformation, most common was an endocardial cushion defect (ECD). 76\% (22/29) had a superiorly oriented $\mathrm{P}$ wave vector. CHB on surface $\mathrm{ECG}$, with a QRS duration of $<.08 \mathrm{msec}$, occurred in $24 \%$ ( $7 / 29$ patients). In 4, CHB was congenital, diagnosed in-utero or early after birth, while 3 pts acquired the CHB during the natural progress of thelr disease. Each of these $7 \mathrm{pts}$ had an ECD with complete absence of the atrial septum. The 4 patients with congenital CHB died hours or days after standard medical or surglcal treatment and permanent pacemaker implantation. The 3 with acquired CHB are alive with permanent pacemaker implant, and two have had complete repair of their intracardiac leston. In conclusion, 1) IIVC should be suspected in pts with superiorly oriented $P$ wave vector on surface ECG; 2) In pts with CHB, IIVC, and abnormal atrial activation, absence of atrial septum should be suspected $(100 \%)$; 3 ) the prognosis is poor if congenttal $\mathrm{CHB}$ is present.
142 EFFECT OF VERAPAMIL ON MECHANICAL FUNCTION OF THE NEONATAL RABBTT HEART Barbara $L$, George, Toshio Nakanishi, Tatsuo Shimizu, Department of Pediatrics, Los Angeles.

Previous data from our laboratory suggest that the newborn (NB) rabbit heart is greatly dependent on extracellular calcium (Ca) for excitation-contraction coupling. Verapam11 (V), a calcium antagonist, is currently being used to treat arrhythmlas in infants. Little is known about the negative inotropic effects of this agent on $\mathrm{NB}$ hearts. This study was designed to evaluate the effects of $V$ on mechanical function of the neonatal heart. $N B \quad(n=6)$ and adult $(A, n=6)$ rabbit hearts were studled utilizing an isolated, arterlally perfused cardlac preparation that was maintained at $27^{\circ} \mathrm{C}$ and paced at 36 beats $/ \mathrm{min}$. The muscles were perfused Initially with a control Krebs-Henseleit solution (K-HS) and then with a $\mathrm{K}-\mathrm{HS}$ containing 0.1 uM of V. Peak (PT), developed (DT), resting (RT) tensions; rate of tension development (+dT/dt); time to peak tension (TPT); and time to half relaxation (1/2 RLT) were recorded contintously. The negative inotropic effect of $\mathrm{V}$ in the NB was significant1y $(P<0.01)$ less than that in the $A$. In the $N B, 50 \%$ of the maximal decrease in function occurred significantly $(\mathrm{P}=0.03)$ later than it did in the A. V significantly $(P<0.04)$ increased the RT in the NB but not in the A. V had no significant effect on either the TPT or the 1/2 RLT in the two age groups. These data suggest that the negative Inotropic effect of $V$ in the NB is less than that in the $\mathrm{A}$ and that the $\mathrm{NB}$ is less dependent on the slow inward calcium current for excitation-contraction coupling than is the $A$.

143 SYSTEMIC VASCULAR HISTAMINE RECEPTORS. B. W. Goetzman, J.M. Milstein, $\frac{S . H . \text { Bennett. Univ. of Calif- }}{\text { ornia, Davis, School of Med., Dept. of Pediatrics. }}$

Histamine $\mathrm{H}_{1}$ - and $\mathrm{H}_{2}$ - receptor mediated changes in systemic vascular resistance were evaluated in 10 newborn lambs (0-3 days of age). Lambs were anesthetized with chloralose and instrumented to allow for continuous measurement of systemic vascular resistance (SVR), cardiac output (CO) and heart rate (HR). Histamine was injected into the main pulmonary artery in doses ranging from 0.01 to $1.0 \mu \mathrm{g} / \mathrm{kg}$ of histamine base. In each lamb, histamine dose response curves were generated for SVR, HR and stroke volume (SV) and repeated in 6 lambs after the administration of the $\mathrm{H}_{1}$-receptor antagonist, diphenhydramine, and/or the $\mathrm{H}_{2}$-receptor antagonist, cimetidine. The major effect of histamine on SVR, a decrease of $20-22 \%$, occurred at a dosage of 0.6 $\mu \mathrm{g} / \mathrm{kg}$. No effect was noted on SVR below a dose of $0.05 \mu \mathrm{g} / \mathrm{kg}$. HR increased by $10-15 \%$ at these same dosages. No effect on SV was observed. The $\mathrm{H}_{1}$-receptor antagonist decreased the SVR response significantly and had a small effect on the HR response. The $\mathrm{H}_{2}$-receptor antagonist had no effect on the SVR response and a major effect on the HR response. Thus, $H_{7}$-receptors appear to mediate systemic vascular relaxation in the newborn lamb and $\mathrm{H}_{2}$-receptors mediate cardiotonic changes. The dosage range required to produce these effects was an order of magnitude larger than those we previously reported as having significant effects on pulmonary vascular resistance. In addition $\mathrm{H}_{2}$-receptors appear to be less important in the SVR response of newborns as compared to adults.

\section{DYSRHYTHMIAS IN CHILDREN}

Arthur Garson, Jr, Paul C. Gillette; Baylor College of Medicine, Texas Children's Hospital, Lillie Frank Abercrombie Section of Cardiology, Dept of Pediatrics, Houston

Dilantin (D) is one of the most effective drugs in the treatment of ventricular dysrhythmias (VDYS) in children. Even with a loading dose, $48 \mathrm{hrs}$ of oral treatment are required before an effective serum concentration (SC) of $15-20 \mathrm{mcg} / \mathrm{ml}$ is achieved. To accelerate this process, we have developed an intravenous (IV) loading dose protocol accompanied by oral therapy. Over $1 \mathrm{hr}$, $15 \mathrm{mg} / \mathrm{kg}$ is given IV. Every $5 \mathrm{~min}, 1 / 13$ of the total dose is pushed, undiluted, and cleared from the tubing with normal saline. At the same time, oral $D$ is begun with $3 \mathrm{mg} / \mathrm{kg}$, followed $6 \mathrm{hrs}$ later by $2 \mathrm{mg} / \mathrm{kg}$ and $6 \mathrm{hrs}$ later, maintenance oral $\mathrm{D}: 2.5-3.0 \mathrm{mg} / \mathrm{kg}$ ql2h. We administered IV D to 19 pts who had an abnormal heart and VDY (mean age 12.9yrs; range 1wk-24yrs). On 24-hr ECG before Rx, 6 had VT, 4 couplets, 2 multiform PVC, and 7 frequent uniform PVC (10 or more/ hr). After Rx, 16/19 had none or infrequent uniform PVC $(0-9 / \mathrm{hr})$ and 3 had frequent uniform PVC. D effect on VDYS occurred in $1-2$ hrs in all pts with a SC of $19.8-26.9$. During IV administration, 4 pts became hypotensive; in 3 the protocol could be continued with doses spaced ql5min. We conclude: (1) D is an effective antidysrhythmic agent in children, whether given orally or IV; (2) VOYS can be controlled within $2 \mathrm{hrs}$ of beginning this IV loading protocol; (3) because of the possibility of hypotension, IV $D$ should not be given to pts with cardiac decompensation and should be given cautiously over several hrs in pts with severely abnormal hemodynamics. COMPARISON OF THE SENSITIVITY OF M-MODE CONTRAST AND
DOPPLER CONTRAST Stanley J. Goldberg, Lilliam M.

144 Valdes-Cruz, Hugh D. Allen, David J. Sahn, Linda

Feldman, University of Arizona, Department of Pediatrics, Tucson

U1trasonic contrast techniques allow tracking of blood flow in patients with cardiac malformations. One problem of ten encountered in M-mode contrast is 1nability to generate adequate microbubbles for recording. To test if echo Doppler is more sensitive than $M$-mode for detection of microbubbles, results of 63 saline injections were studied at catheterization in 12 patients by simultaneously recording contrast M-mode and echo Doppler studies. Seven other injections were studied with a prototype (PROTO) twodimensional echo Doppler system (Honeywe11). Records were evaluated without identification of the patient. Contrast in the direction of flow was visualized in 61 of 63 infections by echo Doppler. In these, a frequency dispersion was present, but even more striking was a marked rise in the time interval histographic input signal strength indicator. Only $36 / 61$ simultaneous M-mode echoes showed a contrast effect $(p<.05)$. In 24 of the disagreements, the M-mode showed no contrast effect whereas the Doppler correctly demonstrated the presence of microbubbles. The PROTO system used Fourier analysis and displayed microbubbles as a low level signal with marked frequency dispersion over the flow pattern. An important difference between M-mode and echo Doppler contrast is that M-mode evaluates contrast at any level along the beam but echo Doppler evaluates only on the range gate. This investigation demonstrated that echo Doppler contrast is more sensitive for detection of microbubbles than M-mode. 